\title{
Social mobility: the influence of the neighbourhood
}

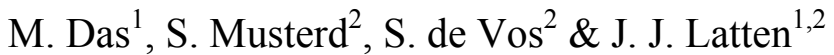 \\ ${ }^{1}$ Statistics Netherlands, The Netherlands \\ ${ }^{2}$ University of Amsterdam, The Netherlands
}

\begin{abstract}
Neighbourhoods in The Netherlands differ strongly in social compositions and in the socio-economic perspectives of their residents. Increasing fears for diminishing social cohesion stimulated policy makers to focus on bettering perspectives for residents in the most disadvantaged neighbourhoods. Neighbourhood intervention strategies in The Netherlands often concentrate on stimulating social and socio-economic mix, by physical restructuring of the neighbourhood. Social mix is assumed to have a positive effect on the upward social mobility of residents because it leads to positive role models in the neighbourhood and creates social bridges. We studied the effects of neighbourhood characteristics - indicators for social level and for social mix on the income development of its residents between 1999 and 2005. We used an integral dataset, register-based and covering the entire Dutch population: the Social Statistical Database of Statistics Netherlands. Multilevel regression analyses showed a small, significant effect of a number of neighbourhood characteristics: income mix, mean income level and, surprisingly, ethnic mix, were positively related to the income development of residents aged 25 to 49 . However, neighbourhood effects were very modest compared to the large influence of individual characteristics. Policymakers in Western Europe and North America involved in urban redevelopment programmes should be aware of that.
\end{abstract}

Keywords: urban policies, neighbourhoods, social mobility, social networks, socialisation, segregation. 


\section{Introduction}

\subsection{Diversity in neighbourhoods}

Dutch neighbourhoods differ strongly in their social composition and the social perspectives of their residents. On a national level income inequality is relatively modest in The Netherlands compared to other countries of the European Union. Still, the incomes of the richest $20 \%$ are four times higher than those of the poorest $20 \%$ (Statistics Netherlands [1]). On regional levels averages in income show much wider ranges, with most low-income neighbourhoods situated in major cities in the west of the country: Amsterdam, The Hague and Rotterdam (Statistics Netherlands [2]). Often - although not always - these income differences are associated with differences in the population composition of neighbourhoods. During recent decades The Netherlands, as many other Western European countries, has undergone a strong demographic transition: the number of non-Western inhabitants increased by more than tenfold (from 160,000 to 1.8 million) between 1972 and 2009, whereas the number of natives increased only by some $10 \%$ (towards 13.2 million). Often, the newcomers were in a disadvantageous economical position and had less social opportunities than the natives. On a lower area-based scale this has resulted in new national contrasts, in which poor neighbourhoods often have above average shares of people with a non-Western background, and rich neighbourhoods are predominantly 'white'. Fears for diminishing social cohesion stimulated Dutch policy makers to focus on bettering perspectives for residents in the most disadvantaged neighbourhoods.

\subsection{Neighbourhood effects: theories and practice}

Neighbourhoods and neighbours could influence the socio-economic prospects of residents via several different mechanisms (reviews by Jencks and Mayer [3], Atkinson et al. [4], Sarkassian et al. [5]). First, Wilson [6] stressed the importance of socialisation processes within neighbourhoods, especially negative socialization processes in neighbourhoods with concentrated poverty. Next to family, school and workplace, the neighbourhood can be seen as an important socialisation 'institute', providing residents with role models. Neighbourhoods with a high share of low income households or with high levels of unemployed or people on benefits have indeed been found to have negative effects on the prospects of residents (Weinberg et al. [7], Van der Klaauw and Van Ours [8]). Second, negative stigmatisation of neighbourhoods may influence residents' prospects, for example during job application procedures (Carpenter et al. [9]). Lastly, social networks within neighbourhoods may influence people's chances. The neighbourhood forms a substantial part of the social network. This holds especially for those with a weak economic position and little other contact opportunities, for instance the unemployed (cf. Middelkoop and Declerck [10]). If these networks are homogenous, people may not be able to establish 'weak ties' with outsiders - people with a higher social status that are useful for social 
mobility (cf. Granovetter [11]). In The Netherlands, there is a widespread belief that 'ethnic' segregation will hinder integration in society and social mobility of people with a foreign background because of the resulting differences in social capital. Interestingly, also non-Westerners themselves seem to appreciate some level of ethnic neighbourhood mix, rather than either a predominantly white or black concentration (Souren and Bierings [12]). On the other hand, in the short term recent immigrants may benefit from the proximity to others with the same background, probably because they offer support in finding the ways in their new home country (Murie and Musterd [13], Musterd et al. [14]).

In practice, Western European governments act in line with the theories outlined above: counteracting social problems in cities by trying to influence the social composition of neighbourhoods. Policies aim for social and economic heterogeneity in general, thus reducing concentrated poverty and creating sustainable, socially balanced neighbourhoods. 'Van aandachtswijk naar prachtwijk' (The Netherlands), 'Die Soziale Stadt' (Germany), the 'Urban Task Force and Sustainable Communities' (UK) and the 'Politique de la Ville' (France) are examples of such policies. Usually, a limited number of 'problematic' neighbourhoods are selected and these receive extra policy attention. In many cases, physical restructuring and sale of social or public housing are used to attract the middle class (Murie et al. [15]). In addition, many politicians require that new, larger-scale residential developments must realise a certain minimum share of social (subsidized) dwellings.

\subsection{This study}

In spite of a body of 'neighbourhood effect' literature (e.g. Ellen and Turner [16], Galster [17]), there is still no scientific consensus about the existence of these effects, nor about their magnitude (see Atkinson and Kintrea [18] for a review). This may at least partly be ascribed to the lack of adequate data sources in some of the studies. Atkinson and Kintrea [18] argued that the high demands placed on the datasets were often impossible to meet. Especially the use of crosssectional data instead of dynamical longitudinal data is a methodological handicap. The only large-scale longitudinal studies carried out so far, in Sweden (Andersson et al. [19], Galster et al. [20]), The Netherlands (Musterd et al. [21]) and Britain (Buck [22]), all found at least some neighbourhood influence.

This study aims to add to the knowledge by using a newly available longitudinal dataset on the individual level, which covers the entire Dutch population. The key question is:

How does the composition of the neighbourhood influence an individual's economic prospects -i.e. income development over the subsequent six years- next to his or her individual characteristics?

We aim to fit in with the Swedish research mentioned before, and try to add to the knowledge in at least three ways. First, we will, through our focus on The Netherlands, add to the knowledge about significance of national context. Second, we refine the concept of neighbourhood composition in 'social status' 
and 'social mix'. Hypotheses focusing on social status imply that "the more/less of variable $\mathrm{X}$ in the neighbourhood, the better this is for residents". Many intervention policies, however, do not aim for a high social status of neighbourhoods per se, but aim at social mix, for instance an ethnic mix, or a mix of expensive and cheap dwellings. The (implicit) underlying social mix hypotheses state that "the more mix in variable $\mathrm{X}$ in the neighbourhood, the better this is for residents". With our data, we aim to test both social status and social mix-hypotheses. The third addition is in the methodological sphere. We use multilevel regression analysis, which allows us to disentangle the effects of individual characteristics from neighbourhood effects.

\section{Data and methods}

\subsection{Data}

We used the Social Statistical Database (SSD) of Statistics Netherlands (Bakker [23]). The information in the SSD is derived from a large number of integral registers and a limited number of additional surveys. Data are usually available at the level of the individual, and cover all approximately 16 million Dutch citizens from 1999 to - at the moment of this study- 2005. The following registers are relevant for this study. First, the Dutch population register (GBA) which contains demographic and household information, location of residence and dates of moves, and information on country of origin. Second, the registers on income tax and social security for information about incomes, jobs, social security and pensions. And last, the registers that give information on housing tenure.

The data used in this study contain two sampling moments. The first is ultimo September 1999. All the independent variables - which are individual variables and neighbourhood context variables - are measured at this moment. The second sampling moment is ultimo September 2005. The dependent variable, income development, is constructed by comparing income between the two sampling moments. Income is defined as the sum of all the money a person obtains in the month of the sampling moment from work (monthly wages of the employed, profits/loss for the self- employed), benefits (disability benefits, unemployment benefits, social benefits, other e.g. widow's or orphan's pension), old-age pensions and student grants. Wages are not corrected for the actual number of hours worked in that month. The dependent variable is constructed in the following manner. First the income of September 2005 is divided by the income of September 1999 (both in Euros), then 1 is added, and finally the natural logarithm is taken. To avoid computational and interpretational problems, we analysed only people who have an income of 1 Euro or more in 1999, and 0 Euro or more in 2005. This means we did not include people who started out with no income at all in 1999, for instance housewives.

Seven individual characteristics were used as independent variables, all referring to the situation in 1999: sex, background (based on the country of origin and that of the parents), position in the household, socio-economic 
position (based on the main source of income), housing situation, age, and the (log-transformed) income in September 1999. See the appendix for the categories.

On the neighbourhood level, we used five variables. The median income of all residents of 18 years and older, and the share of residents from 15 till 64 years old living on social benefits, were used as indicators for neighbourhood social status. The inter-quartile distance of income indicated the degree of social mix. The share of people of non-Western background, and the percentage of privately owned homes were incorporated as categorical variables, allowing us to test both the role of social status and the role of social mix for these variables. Social status hypotheses predict a monotonous relation between the variable under study and income development. Social mix hypotheses predict a non-linear, for instance U-shaped relation. More than nine thousand neighbourhoods were included in the analysis. We defined neighbourhood composition by the situation in 1999, and did not account for changes in composition that might have occurred between 1999 and 2005.

\subsection{Methods}

Our analysis was restricted to the age group of 25 to 49-year olds in 1999. These are the people that have finished their education, and are in the middle of their labour market career. We excluded people of 50 and older because we expected the social mobility in that group to be limited: they have already reached the top of their careers. Moreover, a number of them will retire in the period under study. Furthermore, we focused on the non-movers, i.e. the people who lived at the same address in 2005 as they did in 1999. In order to establish a statistical measurable impact of neighbourhood composition on income development, we judged it necessary that the people under study had indeed spent a significant amount of time in their neighbourhood. We realise we probably introduce a selective effect if social climbers tend to leave the neighbourhood -which is likely, see e.g. Latten et al. [24], and Das and de Feijter [25]. Therefore, we should be careful in the interpretation of the results.

In the analysis, we separated those who had a non-substantial income in 1999 (less than 500 Euro in a month) from those who had a substantial income (500 Euro or more in a month). The last group is by far the largest ( 2.8 million people out of a total of 3.1 million) and economically the most important group. Our dataset includes virtually the entire non-movers population within the chosen age and income range, not a sample. We applied multilevel linear regression analysis.

\section{Results}

See the appendix for the descriptive statistics of the variables. There are almost 2.8 million persons who earn 500 Euro or more. Only around 165,000 earn less than 500 Euro. Among those 2.8 million a majority is male, whereas the low income earners are mainly women. This can be explained by the fact that in The 
Netherlands, many women, especially those with young children, work part time in small jobs. In both income strata the majority is employed, but not surprisingly, this share is higher among those with higher incomes. In both income categories the majority of people are married, and have children, but this share is higher among the lower incomes. This is probably related to the high share of part time working women in the lower income stratum.

Table 1 and Table 2 show the results of the multilevel analysis. Table 1 presents the b-estimates of individual variables. Table 2 presents the b-estimates of neighbourhood variables, and the explained variance of three models: the full model, a model with only individual variables, and a model with only individual variables excluding the income in 1999. It is immediately clear that individual characteristics are far more important in the explanation of income development than are neighbourhood characteristics. The percentage of explained variance is larger in the full model than in the model with only individual variables, but only slightly. So, the influence of the neighbourhood is limited at best. Furthermore, the total percentage of explained variance was much lower for the people who already earned 500 Euros or more, the substantial earners, than for the people with a low income. A possible explanation is that the stratum of substantial earners is more heterogenous on one or more unmeasured characteristics that are important for income development, for instance educational level.

Among the individual variables, the income earned in 1999 explained a large part of the variance (Table 2). People who earned little to start with, had a larger income gain than people with higher earnings. This holds true for both income strata (Table 1). Recalling our operationalisation of income development -the ratio between earnings in 2005 and earnings in 1999- this result is not surprising: if you earn little, it is easy to double your income, but this is virtually impossible if you have a high income to start with. As for the other individual variables, the results are by and large in accordance with the expectations. Men have a larger income gain than women, people who are home-owners have larger income gains than people who rent -although this holds only for people who earn a substantial income-, and being employed in 1999 is associated with a larger income gain than living on benefits. With only one exception, the oldest (44-49) have the lowest income gain. In the stratum of people with a substantial income, native Dutch have higher income gain than people with a non-Western background. The low-income stratum gives different results: Most groups with a foreign background have average higher income developments than native Dutch. Individuals with a Moroccan background are the only exception. Household situation was also related to income gain. Most noticeably, married people with children who earned a substantial income had a higher income gain than others with a substantial income, possibly because they are in a stable, undisrupted phase of their lives.

The main focus of this study is on the neighbourhood characteristics. Table 2 shows that higher median income levels and higher income mix in the neighbourhood are both associated with a higher individual income gain of residents. This suggests that residents benefit if their neighbourhood has a high social status, but also if there is a high level of social mix. The results are in line 
Table 1: Income development of the two income strata explained by individual and neighbourhood characteristics; multilevel, b-estimates of individual variables.

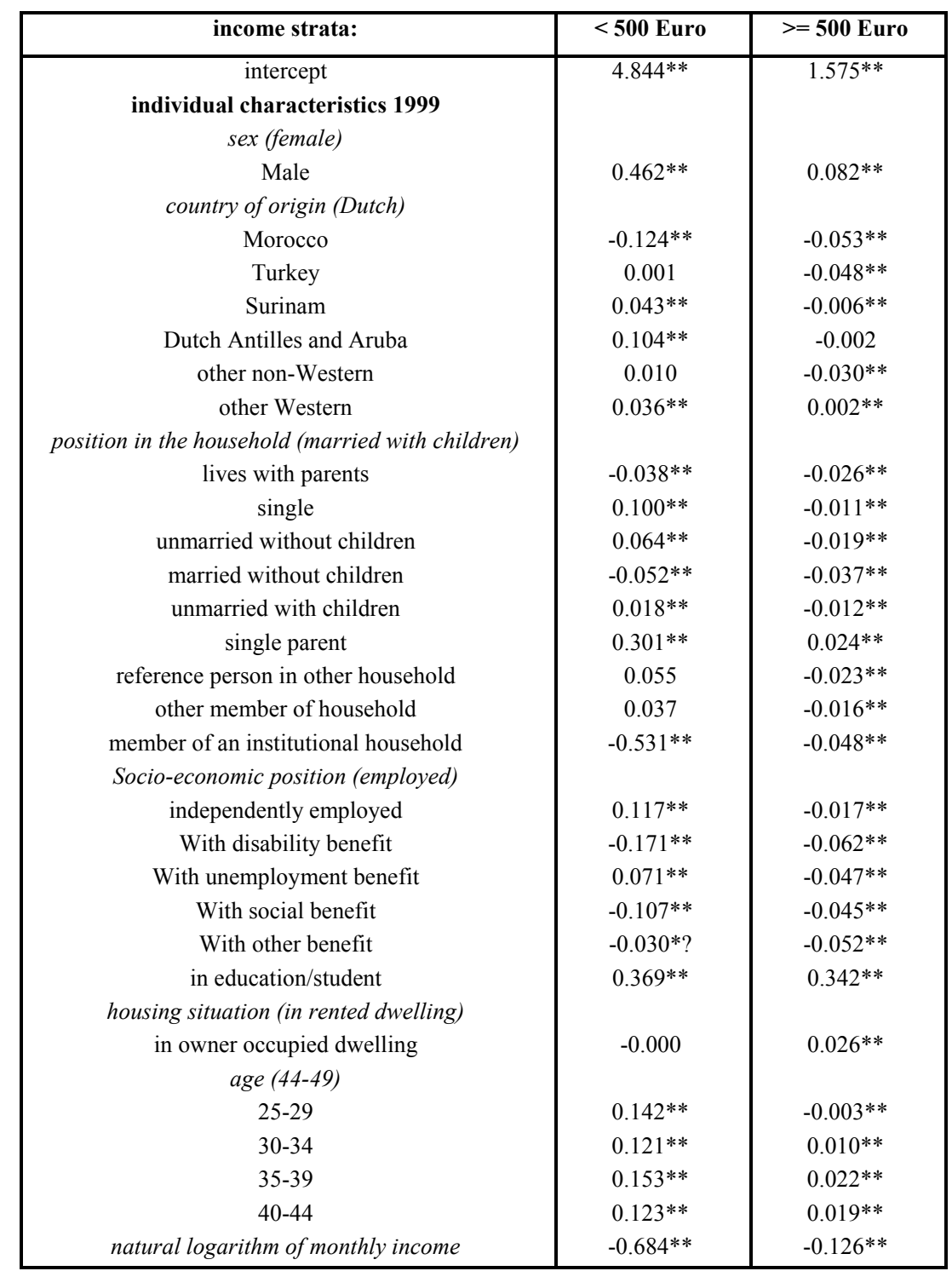

$*: \mathrm{p}<0.05 ; * *: \mathrm{p}<0.01$

The reference categories are between brackets. 
Table 2: Income development of the two income strata explained by individual and neighbourhood characteristics; multilevel, b-estimates of neighbourhood variables.

\begin{tabular}{|c|c|c|}
\hline income strata: & $<\mathbf{5 0 0}$ Euro & $>=\mathbf{5 0 0}$ Euro \\
\hline neighbourhood characteristics 1999 & & \\
\% non-Western origin (0-5) & 0.033 & $0.010^{* *}$ \\
$50-100$ & $0.024^{*}$ & $0.004^{*}$ \\
$25-50$ & $0.025^{* *}$ & $0.003^{*}$ \\
$15-25$ & $0.015^{* *}$ & $0.003^{* *}$ \\
$5-15$ & & \\
\% owner occupied (75-100) & 0.017 & $0.029^{* *}$ \\
$0-25$ & -0.002 & $0.018^{* *}$ \\
$25-50$ & $-0.009^{*}$ & $0.007^{* *}$ \\
$50-75$ & $0.000050^{* *}$ & $0.000023^{* *}$ \\
median income, 18+ yr old & $0.000072^{* *}$ & $0.000047^{* *}$ \\
\% benefits, 15-64 year old & 0.000467 & $0.000232^{* *}$ \\
\hline \% explained variance & & \\
full model & 44.0 & 7.7 \\
only individual variables & 43.8 & 6.8 \\
\hline only individual variables; no income 1999 & 12.0 & 1.8 \\
\hline
\end{tabular}

$*: \mathrm{p}<0.05 ; * *: \mathrm{p}<0.01$

The reference categories are between brackets.

with the neighbourhood socialisation theories, the theories on stigmatisation of neighbourhoods, and also with the social networks theories. Contrary to expectations however, both a higher percentage of benefits and a higher share of rented dwellings had a significant positive influence on income gain of those with a substantial income. Results for the small income stratum were mixed or non-significant. Surprisingly, a high share of non-Western residents was associated with a higher income gain of the residents. Although not all categories were significant, both income strata showed a clear pattern. However, when we repeated the analysis for the non-Western population of residents only (results not shown), we found that for non-Westerners with an income of 500 Euros or more, the relationship was inverse: income gain was larger in 'white' $(0-5 \%$ nonWesterners) neighbourhoods than in more mixed neighbourhoods. For nonWesterners with a low income, there was no significant association between the share of non-Western residents and income development.

\section{Conclusions}

Our research population is selective, especially because we only analysed nonmovers. It is probably not possible to generalize our results for non-movers to 
the entire population. Even so, the non-movers are a very relevant group for policy makers. They are the majority (almost $60 \%$ of the Dutch population did not move between 1999 and 2005) and probably the more stable group. Also, they are the people who benefit the most from neighbourhood restructuring. Possibly, they are also the people who need these programmes the most, since they are unable or unwilling to initiate a move from a less than ideal environment on their own.

Though not all categories were significant, the general picture is that a share of non-western residents in a neighbourhood higher than $5 \%$ was associated with a larger income gain of the residents than a low share. This is surprising, but turned out to only hold true for Dutch and/or people with a Western background. For non-Westerners with a substantial income, income gain is largest in 'white' neighbourhoods, which fits with the theories on social networks. There are no theories that predict a beneficiary effect for native residents of living in neighbourhoods with a large share of non-Westerners or ethnic minorities. A more likely explanation is that the native Dutch population living in such neighbourhoods is a very specific group that is particularly successful on the labour market. For instance, ex-students who still live in their first, cheap, rented apartment may be overrepresented in this group.

As in Sweden (e.g. Andersson et al. [19]) and the UK (Buck [22]), there are significant effects of neighbourhood context in The Netherlands. There was a positive relationship between mix in the neighbourhood -in terms of income- and income gain of the residents. Also, there was a positive relationship between social status of the neighbourhood (again in terms of income) and individual income gain. This is in line with theories on socialisation, social networks and stigmatisation. It seems to support the urban programmes we mentioned before, aimed at creating a social mix and attracting middle class in deprived neighbourhoods to create balanced, sustainable communities.

However, it is important to put these results in perspective. First of all, some of our findings did not match the expectations. But more importantly, the influence of the neighbourhood turned out to be very modest. The most important predictors of income development of non-movers were not neighbourhood characteristics, but individual characteristics. Policymakers in Western Europe and North America involved in urban redevelopment programmes should be aware of that. For an individual, investing in cultural capital through education and employment might be a better way for social advancement than living next to wealthy neighbours. 


\section{Appendix: descriptive statistics for the individual variables of the two income strata}

\begin{tabular}{|c|c|c|}
\hline Income strata: & $<500$ Euros & $>=500$ Euros \\
\hline 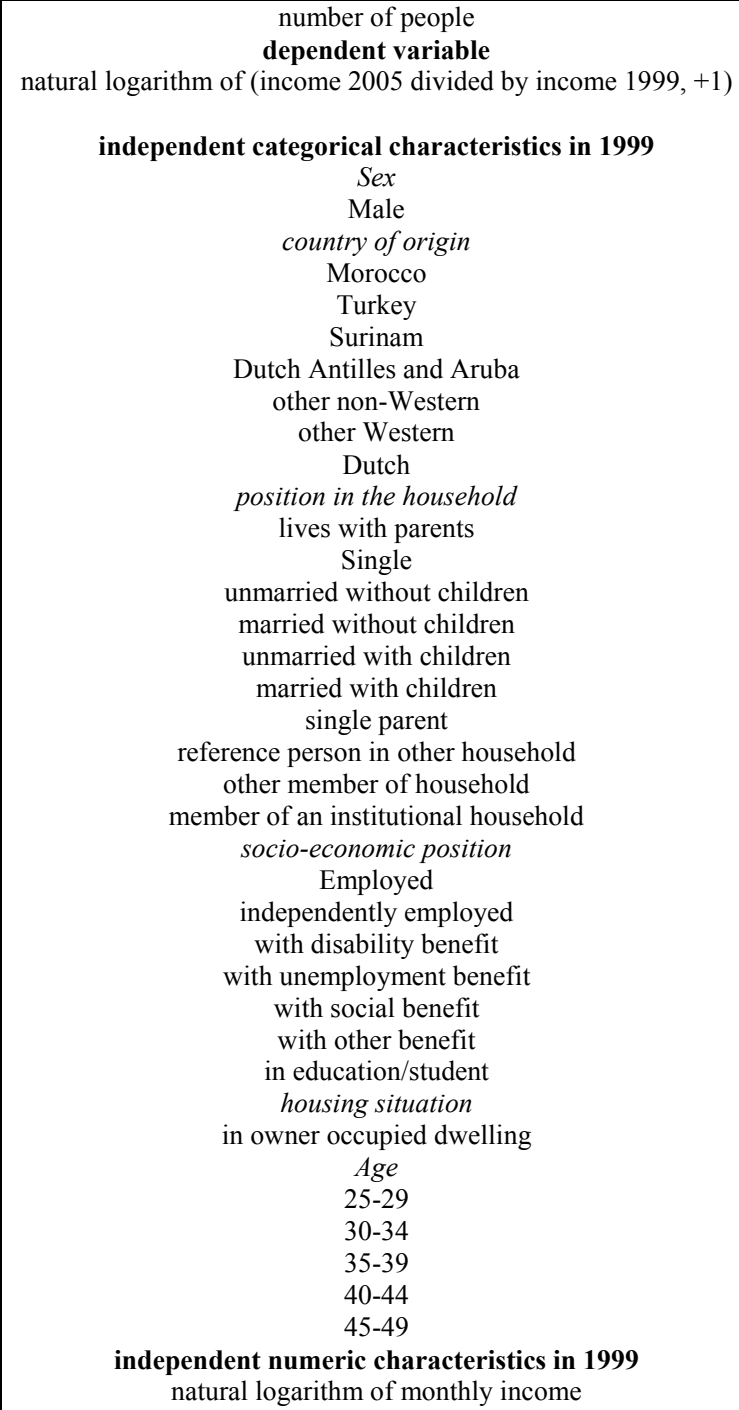 & 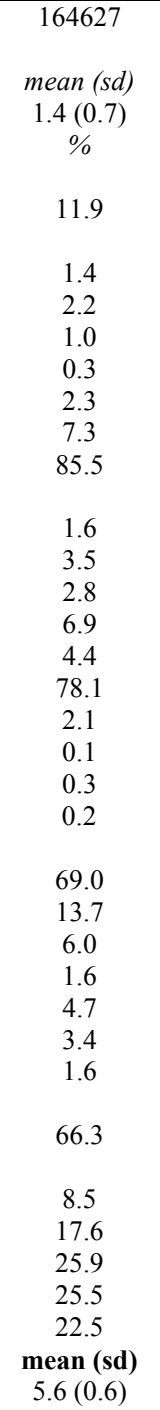 & $\begin{array}{c}2793054 \\
\\
\text { mean (sd) } \\
0.8(0.2) \\
\% \\
\\
59.0 \\
\\
1.1 \\
1.6 \\
2.0 \\
0.5 \\
1.7 \\
7.9 \\
85.3 \\
\\
3.6 \\
12.8 \\
8.8 \\
12.1 \\
4.2 \\
52.7 \\
4.6 \\
0.2 \\
0.5 \\
0.6 \\
\\
82.5 \\
6.9 \\
4.4 \\
0.8 \\
4.1 \\
1.2 \\
0.1 \\
\\
67.8\end{array}$ \\
\hline
\end{tabular}




\section{References}

[1] Statistics Netherlands, De Nederlandse samenleving, Centraal Bureau voor de Statistiek, Den Haag/Heerlen, pp. 158-160, 2008.

[2] Statistics Netherlands, Most people on long-term low incomes live in major cities. Webmagazine, 2008, Online.www.cbs.nl/en-GB/menu/themas/ inkomen-bestedingen/publicaties/artikelen/archief/2008/2008-2465wm.htm

[3] Jenks, C. \& Mayer, S. The Social Consequences of Growing Up in a Poor Neighborhood. Inner-city Poverty in the United States, ed. L.E. Lynn \& M.F.H. McGeary, Washington, DC: National Academy Press, pp. 111-186, 1990.

[4] Atkinson, R., Kintrea, K., Austin, M. D. \& Baba, Y. Disentangling Area Effects: The Contributions of Place to Household Poverty. Urban Studies 38, pp. 2277-2298, 2001.

[5] Sarkassian, W. A. Forsyth \& W. Heine, Residential 'Social Mix': the debate continues, Australian Planner, March 1990, Online. www.sarkissian.com.au/downloads/Articles\%20and\%20Reading\%20Lists/s ocial\%20mix\%20article\%201990.pdf

[6] Wilson, W. J. The Truly Disadvantaged. Chicago IL: University of Chicago Press, 1987.

[7] Weinberg, B. A., Reagan, P. B. \& Yankow, J. J. Do Neighborhoods Affect Work Behavior? Evidence from the NLSY79, forthcoming. Journal of Labor Economics 24, pp.891-924, 2004.

[8] Van der Klaauw, B. \& Van Ours, J.C. From Welfare to Work: Does Neighborhood Matter? Journal of Public Economics 87, pp. 957-985, 2003.

[9] Carpenter, J., Chauviré, Y. \& White, P. Marginalization, Polarization and Planning in Paris. Built Environment 20 (3), pp. 218-230, 1994.

[10] Middelkoop, M. \& Declerck, S., Contact opportunities in neighbourhoods, education and work, (of jaarrapport integratie)

[11] Granovetter, M. The Impact of Social Structure on Economic Outcomes. Journal of Economic Perspectives 19, pp. 33-50, 2005.

[12] Souren, M. \& Bierings, H. Zijn autochtonen en allochtonen tevreden met hun buurtbewoners? Sociaal-economische trends, 4th quarter, pp. 46-50, 2006 Online. www.cbs.nl/NR/rdonlyres/38614D98-B99A-4389-94CC5CEECCC57C17/0/2006k4v4p46art.pdf

[13] Murie, A. \& Musterd, S. Social Exclusion and Opportunity Structures in European Cities and Neighborhoods, Urban Studies 41 (8), pp 1441-1459, 2004.

[14] Musterd, S., Andersson, R., Galster, G. \& Kauppinen, T. Are Immigrants' Earnings Influenced by the Characteristics of their Neighbours? Environment and Planning 40, pp. 785-805, 2008.

[15] Murie, A, Knorr-Siedow, T. \& Van Kempen, R. Large Housing Estates in Europe; General Developments and Theoretical Backgrounds. Utrecht: Restate, 2003. 
[16] Ellen, I. \& Turner, M. Does Neighborhood Matter? Assessing Recent Evidence. Housing Policy Debate 8, pp. 833-866, 1997.

[17] Galster, G. Neighborhood Mix, Social Opportunities, and the Policy Challenges of an Increasingly Diverse Amsterdam. Amsterdam, Netherlands: University of Amsterdam, Department of Geography, Planning, and International Development Studies, 2005, Online. www.fmg.uva.nl/amidst/object.cfm/objectid=7C149E7C-EC9F-4C2E91DB7485C0839425

[18] Atkinson, R. \& Kintrea, K. Disentangling Area Effects: Evidence from Deprived and non-deprived Neighborhoods. Urban Studies 38 (12), pp. 2277-98, 2001.

[19] Andersson, R., Musterd, S., Galster, G. \& Kauppinen, T. What Mix Matters? Exploring the Relationships between Individual's Incomes and Different Measures of their Neighbourhood Context. Housing Studies 22 (5), pp. 637-660, 2007.

[20] Galster, G., Kauppinen, T., Musterd, S. \& Andersson, R. Does Neighborhood Income Mix Affect Earnings of Adults? A New Approach using Evidence from Sweden. Journal of Urban Economics 63, pp. 858870, 2008.

[21] Musterd, S., Ostendorf, W. \& De Vos, S. Environmental Effects and Social Mobility. Housing Studies 18 (3), pp. 877-89, 20032.

[22] Buck, N. Identifying Neighborhood Effects on Social Exclusion. Urban Studies 38, pp. 2251-2275, 2001

[23] Bakker, B.F.M. 'Statistics Netherlands' approach to social statistics: The Social Statistical Dataset" OECD Statistics Newsletter 11 pp 4-6, 2002

[24] Latten, J., Das M. \& Chkalova K. De stad Groningen als roltrap van Noord Nederland. Bevolkingstrends 2., pp. 52-59, 2008.

[25] Das, M. \& de Feijter, H. Wie komen en wie gaan? De nieuwe groei heet krimp. Een perspectief voor Parkstad Limburg, ed. J. Latten \& S. Musterd. Den Haag: NICIS, pp. 57-69, 2009. 